\title{
Effects of moderate electric fields on cold-set gelation of whey proteins - From molecular interactions to functional properties
}

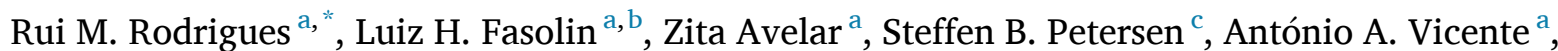 \\ Ricardo N. Pereira ${ }^{a}$ \\ ${ }^{\text {a }}$ CEB - Centre of Biological Engineering, University of Minho, Campus de Gualtar, P-4710-057, Braga, Portugal \\ ${ }^{\mathrm{b}}$ Department of Food Engineering, School of Food Engineering, University of Campinas - UNICAMP, 13083-862, Campinas, SP, Brazil \\ ${ }^{\mathrm{c}}$ Medical Photonics Lab, Department of Health Science and Technology, Faculty of Medicine, Aalborg University, Fredrik Bajers Vej 7, DK, 9220, Aalborg, Denmark
}

\section{A R T I C L E I N F O}

\section{Keywords:}

Ohmic heating

Whey proteins

Proteins functionality

Gelation

Moderate electric fields

\begin{abstract}
A B S T R A C T
Whey protein gelation and final gel properties are dependent of the gel forming solution characteristics (e.g. protein concentration, $\mathrm{pH}$, ionic strength), and physical variables involved in the method used for gel preparation. Ohmic heating $(\mathrm{OH})$ is an emerging technology in food processing and its application in heat-induced gelation of whey proteins has demonstrated its capacity to influence the physicochemical properties of protein gels. In this work, we studied the $\mathrm{OH}$ process and its inherent moderate electric field (MEF) variables - i.e. electric field (EF) strength and frequency - in order to establish their influence in protein aggregation and gelation during WPI cold-set gels formation. The presence of the EF during $\mathrm{OH}$, particularly at higher EF strengths conjugated with lower frequencies, contributed to the formation of smaller aggregates with lower content of reactive thiol groups and lower viscosity. The cold-set gels produced from the aggregates' suspension presented distinctive properties, influenced by the EF variables. - i.e. higher EF strength and lower frequency. EF treatments give rise to more fine-stranded gels with lower disulphide crosslinking but higher number of hydrophobic interactions and hydrogen bonds. The EF effects during the treatments resulted in weaker, more elastic gels with higher water retention and swelling capacity. These results open novel perspectives for the use of $\mathrm{OH}$ as a tool for fine-tuning protein gel networks aiming at enhanced functionality for various applications (e.g. use as texturizer or encapsulating agents).
\end{abstract}

\section{Introduction}

The increasing consumers' demands regarding high quality foods and environmental concerns have triggered the development of emergent technological approaches for food processing. Ohmic heating $(\mathrm{OH})$ is recognised as an emerging high-potential technology for tomorrow (De Vries et al., 2018), having been the aim of considerable research efforts and counting already with a significant industrial presence (Priyadarshini, Rajauria, O'Donnell, \& Tiwari, 2018). OH consists in a heating process based on the application of an electric current to a semi-conductive material (e.g. foodstuff or other biomaterials). As a result, heat deposition occurs directly within the product with a much higher energetic efficiency but also shorter heating times, absence of hot surfaces and reduced temperature gradients, when compared with conventional heating methods (Jaeger et al., 2016; Kaur \& Singh, 2016; Sastry, 2008).
Several studies discuss potential additional synergistic or nonthermal effects resulting from the presence of the moderate electric field (MEF) applied during $\mathrm{OH}$ processing. Particularly whey protein systems have been the focus of the study of MEF effects on protein aggregation and gelation, demonstrating differentiated properties from conventional heating methods (Pereira et al., 2017, 2016; Rodrigues et al., 2015). Despite these reports, the specific action of $\mathrm{OH}$ (and the inherent MEF) on protein aggregation and gelation remains unclear. Recent studies regarding $\mathrm{OH}$ and MEF action during $\beta$-lactoglobulin's the main whey protein fraction - thermal denaturation demonstrated to cause distinctive structural features in the unfolded protein. These changes were dependent on the electrical variables' magnitude (i.e. electric field strength and electrical frequency), and impacted functional properties such as sulfhydryl and hydrophobic groups accessibility, thus affecting protein aggregation and gelation properties (Rodrigues, Vicente, Petersen, \& Pereira, 2019).

\footnotetext{
* Corresponding author.

E-mail address: ruirodrigues@ceb.uminho.pt (R.M. Rodrigues).
} 
During protein gelation, the interactions established between protein molecules are fundamental to the formation of the protein network, and their nature and extent define the final gel properties (Bryant \& McClements, 1998; T.; van Vliet, 2000). In order to potentiate protein interactions an initial denaturation step is often induced by a thermal treatment. Once the protein structure is destabilized, reactive groups are exposed and interact with other proteins, starting aggregation and ultimately gelation (Ramos et al., 2014). If the protein denaturation and initial aggregation steps are carried out in relative low protein concentrations and with predominant electrostatic repulsive forces (i.e. $\mathrm{pH}$ far from the isoelectric point and low salt concentration), the resultant unfolded proteins/aggregates remain soluble at room temperature. The electrostatic balance of these stable dispersions can be changed by modifying the solution's $\mathrm{pH}$ or by adding salts, resulting in protei$\mathrm{n}$ /aggregates interactions and network formation (Amin, Barnett, Pathak, Roberts, \& Sarangapani, 2014; Chi, Krishnan, Randolph, \& Carpenter, 2003). This process is known as cold gelation, and has demonstrated potential to produce highly tuneable gels with distinctive characteristics and with the ability to incorporate thermally liable compounds (Ako, Nicolai, \& Durand, 2010; Guo, 2019; Nicolai, Britten, \& Schmitt, 2011). Furthermore, as aggregation and gelation take place separately, it is possible to study the relationship between aggregates formation and properties and the properties of the final gel (Alting, Hamer, De Kruif, \& Visschers, 2003; Van Vliet, Lakemond, \& Visschers, 2004).

Changes in physical properties of gels affect their functional and sensorial properties, which are a complex function of the raw composition, molecular interactions established between the components, microscopic and mesoscopic structures formed therefrom and ultimately the gel matrix rheological behaviour. The objectives of this work are to study the effects of MEF on the gelation mechanism and functional properties of whey protein isolates (WPI), from the molecular to macroscopic levels. A cold-set gelation process was selected, allowing to evaluate the process effects in the initial denaturation and aggregation step as well as on the final properties of the cold-set gel.

\section{Materials and methods}

\subsection{Materials}

WPI powder (Lacprodan DI-9212) was kindly supplied by Arla Foods Ingredients (Viby, Denmark). The WPI contained 91\% (in dry weight) total protein content and trace contents of lactose (max. $0.5 \%)$ and fat (max. $0.2 \%$ ). Ultrapure water obtained with a Milli-Q Ultrapure water purification system (Millipore, Bedford MA. USA) was used to prepare all solutions. Sodium chloride (ASC reagent grade) supplied by SigmaAldrich (Germany) was used to induce cold gelation of WPI. All other chemicals used were of analytical reagent (AR) grade.

\subsection{Gel preparation}

\subsubsection{Whey protein solutions}

WPI solutions at $7.5 \%(\mathrm{w} / \mathrm{v})$ were prepared in sodium phosphate buffer $\left(0.025\right.$ mol. $\mathrm{L}^{-1}, \mathrm{pH}$ 7) containing $0.02 \%(\mathrm{w} / \mathrm{v})$ of sodium azide. The dispersion was magnetically stirred at room temperature for $2 \mathrm{~h}$ and, if necessary, pH was adjusted to 7 with $\mathrm{NaOH}$ or $\mathrm{HCl} 1 \mathrm{~mol} . \mathrm{L}^{-1}$ solutions. The solutions were then stored overnight at $4{ }^{\circ} \mathrm{C}$ and used on the next day for gels preparation.

\subsubsection{Thermal treatments}

Thermal treatments, $\mathrm{OH}$ and conventional heat exchange (Cov), were performed on a double-jacketed glass cylinder containing stainless steel electrodes at each edge, as described by Pereira, Souza, Cerqueira, Teixeira and Vicente (2010). The treatments were performed for a total of $15 \mathrm{~min}$, composed by a $5 \mathrm{~min}$ heating period and $10 \mathrm{~min}$ of holding at $90^{\circ} \mathrm{C}$. The heating kinetics and thermal profile were kept similar for both types of treatment. For Cov treatments where no electric field was applied, temperature was controlled circulating water in the vessel jacket from a thermo-stabilized water bath. For the $\mathrm{OH}$ treatments, the temperature was controlled by regulating the voltage output of a function generator $(1 \mathrm{~Hz}-25 \mathrm{MHz}$ and $1-10 \mathrm{~V}$; Agilent 33220A, Penang. Malaysia) which was then amplified in an amplifier system (Peavey CS3000, Meridian, MS, USA). In order to evaluate the influence of electric field strength of and electric frequency, four $\mathrm{OH}$ treatments were selected (i.e. $\mathrm{OH} 20 \mathrm{kHz} 10 \mathrm{~V} / \mathrm{cm}, \mathrm{OH} 20 \mathrm{kHz} 20 \mathrm{~V} / \mathrm{cm}, \mathrm{OH} 50 \mathrm{~Hz}$ $10 \mathrm{~V} / \mathrm{cm}$ and $\mathrm{OH} 50 \mathrm{~Hz} 20 \mathrm{~V} / \mathrm{cm}$ ). Temperature was measured with a type K thermocouple (Omega Engineering, Inc., Stamford, CT. USA), connected to a data logger (USB-9161, National Instruments Corporation, Austin, TX. USA). During the treatments the samples were gently stirred (with a magnetic stirrer) to ensure homogeneity. At the end of the treatments, the samples were transferred to screw cap glass tubes and placed in a melting ice bath for $15 \mathrm{~min}$. After reaching room temperature, part of the solutions were collected for aggregate characterization and the remaining were used in gelation experiments.

\subsubsection{Cold gelation}

Cold-set gelation of the thermally treated samples was induced by adding $\mathrm{NaCl} 5$ mol. $\mathrm{L}^{-1}$ solution until a final concentration of $0.2 \mathrm{~mol}$. $\mathrm{L}^{-1}$. The mixture was quickly homogenized, placed in a custom built teflon well plate to produce gel cylinders with $40 \times 1.5 \mathrm{~mm}$ for rheological analysis and in 24 wells (polystyrene plate, wells flat bottom), producing gels with $5 \times 5 \mathrm{~mm}$ for the remaining tests. The gels were let set for $24 \mathrm{~h}$ at room temperature before further analysis.

\subsection{Characterization of protein aggregates and cold-set gels}

\subsubsection{Particle size analysis}

Particle size measurements of the aggregates' solutions were made by dynamic light scattering (DLS) using a Zetasizer Nano (ZEN 3600, Malvern In-struments Ltd., Malvern, U.K.) Samples of WPI aggregates were diluted at 1:10 in the same buffer used for the preparation of WPI solutions, and $1 \mathrm{~mL}$ of the resulting dilute solution were poured into disposable sizing cuvettes. The temperature of the cell was maintained at $25 \pm 0.5^{\circ} \mathrm{C}$ during the measurement. The poly-dispersity index (PDI) derived from cumulants analysis of the DLS measurements was also evaluated and describes the width or the relative variance of the particle size distribution. All measurements were carried out at least in triplicate.

\subsubsection{Determination of accessible sulfhydryl groups}

Determination of the free sulfhydryl groups ( $\mathrm{SH}$ ) in the aggregates' solutions was performed using a modified version of Ellman's DTNB (5.5'-dithiobis-(2-nitrobenzoicacid)) method (Ellman, Courtney, Andres, \& Featherstone, 1961). DTNB solution at $5 \mathrm{mmol} . \mathrm{L}^{-1}$ was prepared in phosphate buffer, $0.1 \mathrm{~mol} . \mathrm{L}^{-1}, \mathrm{pH} 8$ and stored at $4{ }^{\circ} \mathrm{C}$, protected from light. WPI solutions and aggregates' dispersions were diluted in phosphate buffer $\left(0.1 \mathrm{~mol} . \mathrm{L}^{-1}, \mathrm{pH} 8\right)$ to a final concentration of $0.5 \%(\mathrm{w} / \mathrm{v}) .2 .5 \mathrm{~mL}$ of these solutions were transferred to glass test tubes, $100 \mu \mathrm{L}$ of DTNB solution were added, mixed and allowed to react for $1 \mathrm{~h}$ at room temperature. The absorbance at $412 \mathrm{~nm}$ was determined in a UV-VIS spectrophotometer (V-560, Jasco Inc., Tokyo, Japan). All determinations were performed in triplicate and the absorbance of the blank (using buffer instead of protein solution) was subtracted from each sample's absorbance. The total amount of thiol groups was determined using a positive control of the WPI unheated solution produced as described above, but using a 8 mol.L $\mathrm{L}^{-1}$ urea solution at $\mathrm{pH} 8$ instead of the phosphate buffer. The results were expressed as percentage of the total amount of free $\mathrm{SH}$.

\subsubsection{Rheological characterization of aggregate solutions and cold-set gels}

Rheological measurements were performed in triplicate at $25^{\circ} \mathrm{C}$ in a TA Instruments HR-1 rheometer equipped with a Peltier plate (TA Instruments, New Castle, DE). Flow curves were obtained for the aggregate 
solutions using a cone-plate $\left(60 \mathrm{~mm}, 2^{\circ}\right.$ angle, truncation $\left.64 \mu \mathrm{m}\right)$ and performing a three steps program (up-down-up) using a continuous ramp and shear rate range between 0.1 and $300 \mathrm{~s}^{-1}$. The three steps program was carried out in order to eliminate the time-dependence, allowing the system to reach the steady state.

The viscoelastic properties of the cold-set gels were evaluated by oscillatory measurements. Using a plate-plate geometry $(40 \mathrm{~mm}$, $1500 \mu \mathrm{m}$ gap), the frequency sweep tests were performed between 0.1 and $10 \mathrm{~Hz}$, within the linear viscoelasticity domain $(0.5 \%$ strain). Storage complex $\left(G^{*}\right)$ modulus and $\tan \delta\left(G^{\prime \prime} / G^{\prime}\right)$ were evaluated.

Mechanical properties were determined by uniaxial compression measurements using a TA HD Plus Texture Analyzer (Stable Micro Systems. UK) with an aluminium $25 \mathrm{~mm}$ probe. The force used to compress $80 \%$ of the initial height was measured using a crosshead speed of $1 \mathrm{~mm} / \mathrm{s}$. A trigger force of $0.05 \mathrm{~N}$ was used and at least 10 samples of each experimental condition were tested.

From the force-deformation data, Hencky stress $\left(\sigma_{H}\right)$ and strain $\left(\varepsilon_{H}\right)$ were calculated according to Equations (1) and (2), respectively (Steffe, 1996). The gel rupture point was evaluated by the maximum peak of the stress-strain curve, and the Young's modulus $(E)$ was the slope of the first linear interval ( $0-5 \%$ deformation) of the stress-strain curve (Rosenthal, 1999; Steffe, 1996).

$\sigma_{H}=F(t) \times \frac{H(t)}{H_{0} A_{0}}$

$\varepsilon_{H}=-\ln \left[\frac{H(t)}{H_{0}}\right]$

where $F(t)$ is the force at time $t ; A_{0}$ and $H_{0}$ are the initial area and height of the sample, respectively; and $H(t)$ is the height at time $t$.

\subsubsection{Microscopy study of the cold-set gels structure}

Cold-set gels microstructure was investigated by Confocal Laser Scanning Microscopy (CLSM). Before the cold-set gels preparation, protein aggregates' solutions obtained by thermoelectric treatment were stained with rhodamine B isothiocyanate obtained from Sigma (R1755). After the staining procedure, the cold-set gel was prepared and mounted on a microscope slide, covered with a slip and hermetically sealed to prevent evaporation. The microstructure of the samples was analysed $24 \mathrm{~h}$ after the preparation. The images were acquired in a Confocal Scanning Laser Microscope (Olympus BX61, Model FluoView 1000 Version 4.2.1.20), in fluorescent mode (laser excitation line $559 \mathrm{~nm}$ and emission filters BA 575-675, red channel), using the program FV1000Ver4.2.1.20 (Olympus).

\subsubsection{Protein solubility}

The protein solubility of WPI gels was determined in five different solvent systems: in phosphate buffer 0.025 mol.L-1, pH 7 (PB), PB and $1 \%$ sodium dodecyl sulphate (SDS), PB and Urea 8 mol.L-1 (U), PB and $0.2 \%$ 2-mercaptoethanol (2-Me) and the conjugation of all the previous. Cylindrical gel samples of $5 \times 5 \mathrm{~mm}(\approx 0.5 \mathrm{~g})$ were individually weighed, placed in glass screwcap tubes and $5 \mathrm{~mL}$ of each one of the solutions added. The experiments took place under agitation on an orbital shaker (KL-2 Edmund Buhler. Germany) at $60 \mathrm{rpm}$ at room temperature during a period of 5 days. At days 1, 3 and 5, the samples were centrifuged at $3421 \subseteq$ g for 5 min on an EBA 20 centrifuge (Andreas Hettich GmbH \& Co.KG. Tuttlingen, Germany). After centrifugation, supernatant fractions were recovered and the soluble protein determined by absorbance at $280 \mathrm{~nm}$ on a UV-VIS spectrophotometer (V-560. Jasco Inc.. Tokyo. Japan) using and absorbance coefficient of $0.9565 \mathrm{~g}-1 \mathrm{~cm}-1$.

\subsubsection{Water-holding capacity (WHC)}

WHC of the gels was determined by weighing $5 \times 5 \mathrm{~mm}$ cylindrical samples $(\approx 0.5 \mathrm{~g})$ before and immediately after centrifugation. The gels were placed on top of 3 layers of Whatmann \# 1 filter papers (Maidstone,
UK), placed in centrifuge tubes and centrifuged at $25^{\circ} \mathrm{C}$ and $250 \times \mathrm{g}$ for 5 min using an EBA 20 centrifuge (Andreas Hettich GmbH \& Co.KG. Tuttlingen, Germany). The WHC was determined by the relation of the water released into the filter paper and the water in the gel before centrifugation, according to Equation (3).

$W H C=100 \times\left[1-\left(\frac{w_{r}}{w_{g}}\right)\right]$

Were $w_{r}$ is the mass of water released and $w_{g}$ is the initial mass of water contained on the gel.

\subsubsection{Swelling degree}

The swelling degree of the gels was determined on $5 \times 5 \mathrm{~mm}$ cylindrical samples $(\approx 0.5 \mathrm{~g})$. Samples were weighted before submerging them in $5 \mathrm{~mL}$ of the same buffer used for the preparation of WPI solutions. After $24 \mathrm{~h}$ soaking at room temperature, the samples were removed from the buffer solution. The excess of liquid left on the gel surface was gently removed with filter paper and the samples were weighted. The swelling degree was expressed in percentage according to Equation (4).

Swelling ratio $(\%)=\frac{W_{s}-W_{i}}{W_{i}} \times 100$

Were $W_{s}$ is the mass of the swollen gel and $W_{i}$ in the initial gel mass.

\subsection{Data analyses}

All data analysis, fitting, plotting and statistical analysis procedures were performed on Origin 8.1 software (OriginLab Corporation. Northampton. MA. USA). Unless otherwise stated all experiments were run at least in triplicate.

\section{Results and discussion}

\subsection{Aggregates characterization}

\subsubsection{Particles size and $\mathrm{SH}$ accessibility}

The first stage of protein cold-gelation consist on protein denaturation and aggregation into a stable aggregates' suspension. The aggregation extent and disulphide interactions are the key factors to define the gel properties once cold gelation is induced (Ako et al., 2010; Alting, Hamer, de Kruif, Paques, \& Visschers, 2003). The effects of the thermo-electric treatments on WPI aggregation and SH groups accessibility are presented in Table 1 .

The thermo-electric treatments caused radical changes on the WPI solution, leading to the decrease of PdI, increase in particle size and free $\mathrm{SH}$ content. This demonstrated that for all the treatment conditions applied, protein aggregation was induced and SH interactions potentiated, achieving suitable conditions to promote cold gelation. Cov

Table 1

Hydrodynamic size diameter $\left(Z_{\text {avg }}\right)$, polydispersity index $(P d I)$ and free $\mathrm{SH}$ groups of whey protein solution and aggregates.

\begin{tabular}{llll}
\hline Sample & $Z_{\text {avg }}(\mathrm{nm})$ & PdI & $\begin{array}{l}\text { Accessible Sulfhydryl } \\
\text { Groups (\%) }\end{array}$ \\
\hline Unheated WPI & $15.390 \pm 2.399^{\mathrm{a}}$ & $0.592 \pm 0.030^{\mathrm{a}}$ & $14.308 \pm 1.336^{\mathrm{a}}$ \\
$\mathrm{Cov}$ & $152.467 \pm 1.786^{\mathrm{b}}$ & $0.439 \pm 0.057^{\mathrm{b}}$ & $86.774 \pm 1.105^{\mathrm{b}}$ \\
OH $20 \mathrm{kHz}$ & $137.202 \pm 3.541^{\mathrm{c}}$ & $0.423 \pm 0.018$ & $81.940 \pm 2.182^{\mathrm{c}}$ \\
$10 \mathrm{~b} / \mathrm{cm}$ & & $\mathrm{bc}$ & \\
OH $20 \mathrm{kHz}$ & $127.9124 .678^{\mathrm{d}}$ & $\begin{array}{l}0.399 \pm 0.058 \\
\text { bc }\end{array}$ & $80.104 \pm 1.481^{\mathrm{c}}$ \\
$\quad 20 \mathrm{~V} / \mathrm{cm}$ & & & \\
OH $50 \mathrm{~Hz}$ & $121.703 \pm 4.248^{\mathrm{d}}$ & $0.349 \pm 0.059^{\mathrm{c}}$ & $72.601 \pm 3.721^{\mathrm{d}}$ \\
$10 \mathrm{~V} / \mathrm{cm}$ & & & \\
OH $50 \mathrm{~Hz}$ & $118.817 \pm 1.867^{\mathrm{e}}$ & $0.349 \pm 0.032^{\mathrm{c}}$ & $68.216 \pm 2.856^{\mathrm{e}}$ \\
$20 \mathrm{~V} / \mathrm{cm}$ & & & \\
\hline
\end{tabular}

For each column, different letters correspond to statistically significant differences $(\mathrm{p}<0.05)$. 
heating treatments resulted in aggregates with the higher size and polydispersity index, while $\mathrm{OH}$ treatments resulted in significant $(p<0.05)$ reduction of the aggregates size and size distribution comparing to COV. The aggregates obtained under Cov treatment also presented higher content of accessible SH groups. SH groups are expected to be exposed during thermal denaturation, becoming available to establish disulphide bonds with other $\mathrm{SH}$ groups from the same or other protein molecules. MEF-exposed samples presented lowered SH accessibility, which suggests the involvement of these groups in disulphide bonds. If disulphide crosslinking was enhanced during the aggregation process under MEF, it is possible that their stabilization was faster and thus promoting aggregates of smaller dimensions and lower polydispersity. These results are in line with previous studies on the $\mathrm{OH}$ effect in WPI gelation, where the application of this emerging technology resulted in reduced aggregation, narrower size distributions and lower amounts of free SH groups accessibility (Pereira et al., 2016; Rodrigues et al., 2015). For the first time different levels of EF strength and electric frequency were evaluated in WPI aggregation. The use of $\mathrm{OH}$ at $20 \mathrm{kHz}$ and $10 \mathrm{~V} / \mathrm{cm}$ resulted in a $15 \mathrm{~nm}$ average size reduction compared with the Cov treatment and the increase of EF strength to $20 \mathrm{~V} / \mathrm{cm}$ resulted in an additional reduction of $10 \mathrm{~nm}$, however no significant differences were observed in the polydispersity index. Under the same conditions, the SH groups' accessibility was also significantly reduced when compared with the Cov treatment, but without differentiation between the two EF strengths applied. The use of treatments with an electric frequency of $50 \mathrm{~Hz}$ resulted higher differentiation from the Cov treatments. The average aggregate size was reduced up to $34 \mathrm{~nm}$ and the SH accessibility reduced by $19 \%$ for the $\mathrm{EF}$ at $20 \mathrm{~V} / \mathrm{cm}$. The aggregates obtained under $50 \mathrm{~Hz} \mathrm{OH}$ were also less polydisperse than the ones obtained by Cov, but not significantly different from those of $\mathrm{OH}$ at $20 \mathrm{kHz}$. It is clear that the $\mathrm{OH}$ treatments, with a significant influence of the electric frequency applied and electric field strength used, resulted in differentiated aggregation and disulphide crosslinking potential.

\subsubsection{Rheological properties of the aggregates' solutions}

Once the effects of $\mathrm{OH}$ and its variables in the WPI aggregation and $\mathrm{SH}$ accessibility were verified, it was also expected that these effects could result in differentiation in terms of the mechanical properties of the aggregates' suspensions. Fig. 1 shows the flow curves of shear stress as a function of shear rate for the aggregates' solutions produced under different thermoelectric conditions.

As expected, the changes produced at molecular level by the thermoelectric treatments and their variables, resulted in observable effects on the flow behaviour of the aggregates suspensions. The unheated WPI solution presented an apparent linear behaviour, while the aggregates' solutions presented a typical pseudoplastic behaviour (Ton Van Vliet et al., 2004). Within this group, it is also clear the differentiation between $\mathrm{Cov}$ and $\mathrm{OH}$ treatments, as well as between the $\mathrm{OH}$ treatments produced under different conditions. In order to understand the flow behaviour of the fluid samples, the power-law model was adjusted to the experimental data obtained through Equation (5).

$\sigma=K \cdot \dot{\gamma}^{n}$

where $\sigma$ is shear stress $(\mathrm{Pa}), \dot{\gamma}$ is shear rate $\left(\mathrm{s}^{-1}\right), K$ is consistency index $\left(\mathrm{Pa} \cdot \mathrm{s}^{-1}\right)$, and $n$ is flow behaviour or power-law index. Different flow behaviours between the unheated WPI solutions and the thermo-electric produced aggregates were confirmed by the fitting parameter presented in Table 2.

The different behaviour of the unheated WPI solution observed in Fig. 1 translated into a low consistency index, demonstrating the absence of a structured system and thus of interactions between the solution constituents. The $n$ value obtained is close to 1 , confirming a linear behaviour, in agreement with a Newtonian fluid. For all the treated samples the $n$ value obtained was lower than 1, confirming the pseudo-plastic nature of the fluids. Moreover, all the $\mathrm{OH}$ treated samples presented an increase of the $n$ value, increasing also with the EF strength and low frequency. This increase in the $\mathrm{n}$ value revealed on a flow behaviour moving towards a Newtonian flow. Parameter $K$ is related to the solution's viscosity and was significantly lower for the samples produced under $\mathrm{OH}$, reducing up to approximately five times under $\mathrm{OH}$

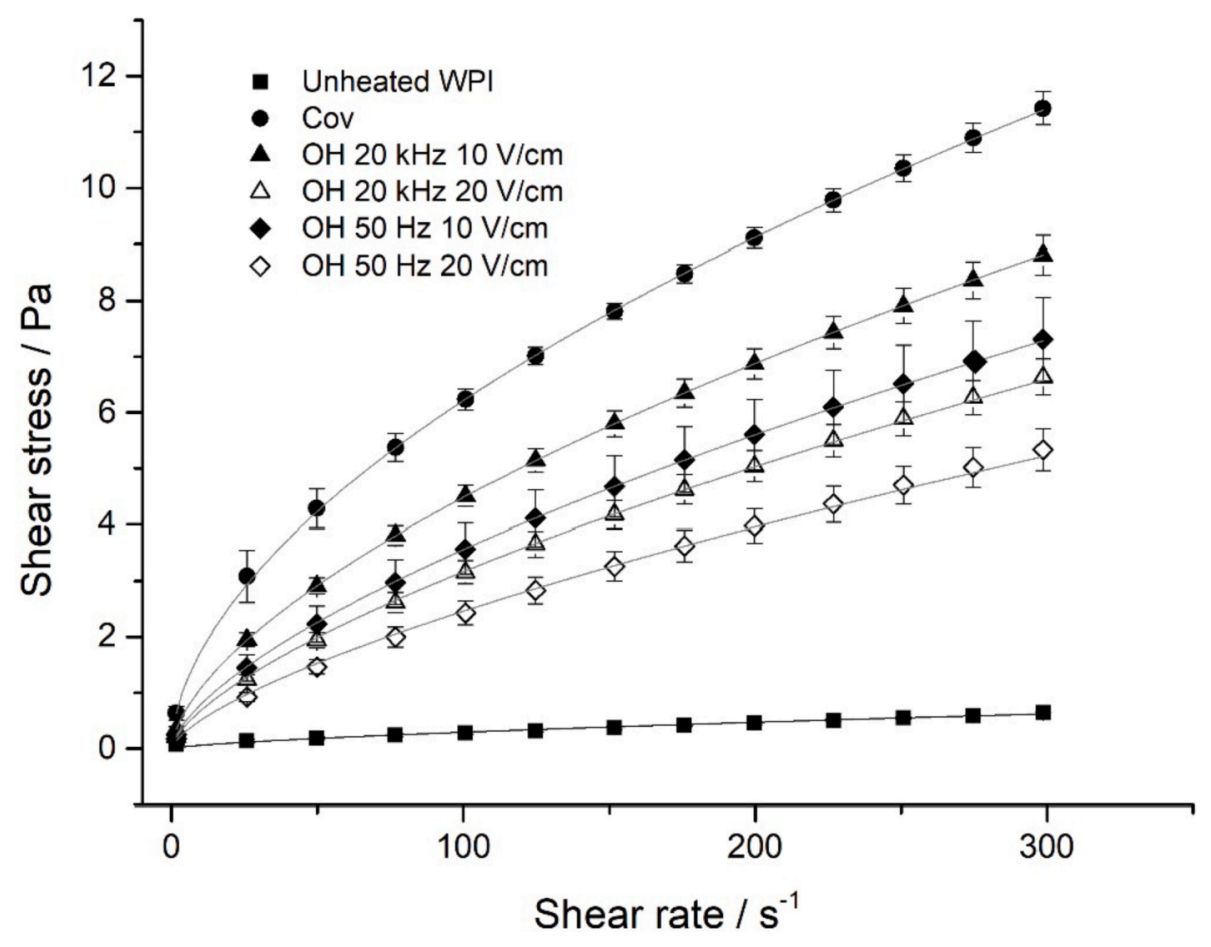

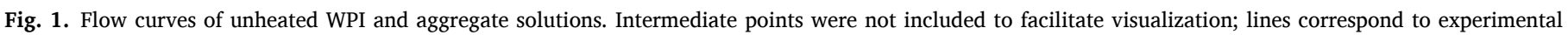
data fitting. 
Table 2

Power law fitted parameters to the flow curves.

\begin{tabular}{lll}
\hline \multicolumn{1}{l}{ Samples } & \multicolumn{1}{l}{ Parameters } & \\
\cline { 3 - 3 } & $K\left(\right.$ Pa.s $\left.^{-1}\right)$ & $n$ \\
\hline Unheated WPI & $0.0023 \pm 0.0003$ & $0.962 \pm 0.028$ \\
$\mathrm{Cov}$ & $0.469 \pm 0.076^{\mathrm{a}}$ & $0.563 \pm 0.034^{\mathrm{a}}$ \\
$\mathrm{OH} 20 \mathrm{kHz} 10 \mathrm{~V} / \mathrm{cm}$ & $0.263 \pm 0.025 \mathrm{~b}$ & $0.617 \pm 0.014 \mathrm{~b}$ \\
$\mathrm{OH} 20 \mathrm{kHz} \mathrm{20V/cm}$ & $0.134 \pm 0.018^{\mathrm{cd}}$ & $0.685 \pm 0.017^{\mathrm{c}}$ \\
$\mathrm{OH} 50 \mathrm{~Hz} \mathrm{10V/cm}$ & $0.170 \pm 0.042^{\mathrm{d}}$ & $0.678 \pm 0.035^{\mathrm{c}}$ \\
$\mathrm{OH} 50 \mathrm{~Hz} \mathrm{20V/cm}$ & $0.087 \pm 0.013^{\mathrm{c}}$ & $0.709 \pm 0.037^{\mathrm{c}}$ \\
\hline
\end{tabular}

For each column, different letters correspond to statistically significant differences $(\mathrm{p}<0.05)$. All correlation coefficients of model fitting to experimental data were $>0.99$.

at $50 \mathrm{~Hz}$ and $20 \mathrm{~V} / \mathrm{cm}$. Both the increase of EF strength and the use of low frequencies produced significant effects on the $K$ value and consequently, viscosity reduction. We have previously established that the use of $\mathrm{OH}$, as well as the increase of EF strength and use of low frequency, resulted on aggregates' size reduction, which contributes to the lower viscosity of the suspensions. Furthermore, the use of OH during WPI aggregation led to changes in the aggregates' morphology, resulting in more elongated, fibrillar-like aggregates (Pereira et al., 2016). These differences could also contribute to the observed differences in the flow behaviour, as the elongated aggregates possibly will align with the direction of the force applied and produce less resistance, also resulting in lower viscosity of the suspensions.

\subsection{Cold-set gels characterization}

\subsubsection{Gels microstructure}

The effects of different thermo-electric pre-treatments on the gel microstructure were investigated by CLSM. Representative images of the different gels produced are presented in Fig. 2. The samples exhibited a typical gel structure composed by the protein network, here stained by rhodamine. Cov samples presented an amorphous structure with compact continuous areas. In $\mathrm{OH} 20 \mathrm{kHz}$ samples it was possible to observe similar compact structures but with smaller size. It was also observed the formation of regular patterns on the structure with a more homogeneous appearance. The $\mathrm{OH} 50 \mathrm{~Hz}$ did not present compact areas and displayed a finer stranded pattern with uniform appearance. It is clear that the exposure to MEF during the thermal pre-treatment and aggregation resulted in modifications on the gelation process and gel structure. MEF effects resulted in gels with a finer structure, more evident when low frequencies and higher EF were applied. As previously discussed, $\mathrm{OH}$ treated samples presented smaller aggregates with lower amount of free SH groups. These differences on the aggregates in the gel forming solution imply different assembly of the network and potentially different physicochemical interactions established within it, resulting on the differences in microstructure observed here.

\subsection{Small amplitude oscillatory dynamic rheology}

Viscoelastic properties of the cold-set gels formed depended on both the microstructure of the gel and the interactions between the aggregating particles. Changes in the gels viscoelastic characteristics were expected, considering the differences in the aggregation, SH accessibility and microstructure induced by different thermo-electric treatments. To confirm the cold-set gel formation and evaluate its viscoelastic behaviour, a frequency sweep of $G^{*}$ modulus and $\tan \delta$ in the viscoelastic linear region was performed (see Fig. 3). The analysis of $G^{*}$ shows, with similar trends for all samples, a small increase with the increase in angular frequency. Typically, stronger gels originate from chemical crosslinking and the viscoelastic moduli do not show frequency dependency, while weaker gels depend on physical interactions, display viscoelastic moduli with great frequency dependency. The small dependency of $G^{*}$ on the frequency characterizes a soft gel, sustained by a combination of chemical crosslinking and physical interactions (Ross-Murphy, 1995). A clear differentiation between the $\mathrm{OH}$ and Cov samples is evident, with the higher values of $G^{*}$ for Cov samples translating in a stronger structure. Fig. 3B shows the variation of $\tan \delta$ with the frequency sweep. The viscoelastic behaviour of the obtained cold-set gels was characterized by the predominance of the elastic component and thus confirming the formation of a gel. The determined $\tan \delta$ values are similar for all the gels obtained, their magnitude just above 0.1 and with little frequency dependence are typical of a fine structure gel, (Mleko \& Foegeding, 2000; Ross-Murphy, 1995; Savadkoohi \& Farahnaky, 2012). The gels submitted to $\mathrm{OH} 50 \mathrm{~Hz} 20 \mathrm{~V} / \mathrm{cm}$ treatments, despite the proximity to the other samples, presented higher $\tan \delta$ values with tendency to increase in higher frequencies. This denotes an increase of the viscous component or a possible damage of the structure, which is compatible with a weaker structure.

The analysis of the viscoelastic moduli at the reference frequency of $1 \mathrm{~Hz}$ demonstrated significant differences induced by the thermoelectric treatments performed on the gel forming solutions (Table 3 ). Despite of the similar general behaviour of the samples - see Fig. 2 - $G^{*}$ was higher for Cov samples, revelling a higher structured system. For $\mathrm{OH}$ samples, the use of different electric frequencies resulted in the differentiation of gel strength, presenting $G *$ values $23 \%$ and $37 \%$ lower than Cov, for $20 \mathrm{~Hz}$ and $50 \mathrm{~Hz}$ respectively. The increase of the EF strength from 10 to $20 \mathrm{~V} / \mathrm{cm}$ despite of apparently contributing to the viscoelastic moduli reduction, did not reach statistical significance.

\subsubsection{Mechanical properties}

Fig. 4 represents the mechanical properties of the cold-set gels obtained. Cov samples displayed the lowest strain at rupture and the samples subjected to $\mathrm{OH}$ treatment presented an increasing tendency of the strain at rupture values, however the increase was only statistically significant for the $\mathrm{OH}$ treatment at $50 \mathrm{~Hz}$ (independently of the electric field strength applied - see Fig. 4A). Cov samples displayed the highest stress at rupture, significantly higher than the $\mathrm{OH}$ samples (see Fig. 4B). The EF increase and use of low frequencies contributed to the reduction of the stress at rupture, only reaching statistical significance for the $\mathrm{OH}$ treatment at $50 \mathrm{~Hz}$ and $20 \mathrm{~V} / \mathrm{cm}$. Overall, it is possible to conclude that Cov-treated samples presented a stronger and more rigid structure, as they break at lower strains but under higher stress and OH-treated samples had a weaker and more elastic structure, breaking under lower stress and at higher strains. These properties were reflected on the values of Young's modulus, representing the firmness of the network at low deformation. The significantly higher moduli observed for Cov gels translate into a more solid-like behaviour and higher capacity to store the applied force, while the $\mathrm{OH}$ treatment, together with the increase of EF strength and the use of lower electric frequencies contribute to a reduction of Young's moduli. The mechanical properties of the gels were consistent with the results obtained from oscillatory rheology tests and the same general pattern was also observed for the gels mechanical properties' variations with the thermo-electric treatment applied.

\subsubsection{Network interactions}

By itself, the formation of a gel network composed by smaller particles and with different $\mathrm{SH}$ crosslinking potential is enough to explain the differences observed in the cold-set gel rheological, mechanical and functional properties. However, once the net-charge of the aggregate dispersions was changed and the cold-gelation process started, the interaggregate interactions - e.g. hydrogen bonds, hydrophobic interactions also play a decisive role in network formation. In order to determine the contribution of different interactions established during the network formation process and their contribution for the gel properties, gel solubility was evaluated in different solvent systems designed to disrupt specific bonds and interactions. Agents such as sodium dodecyl sulphate, which disrupts hydrophobic interactions, urea at $8 \mathrm{~mol} . \mathrm{L}^{-1}$, which disrupts hydrogen bonds and destabilizes hydrophobic interactions, and 2- 

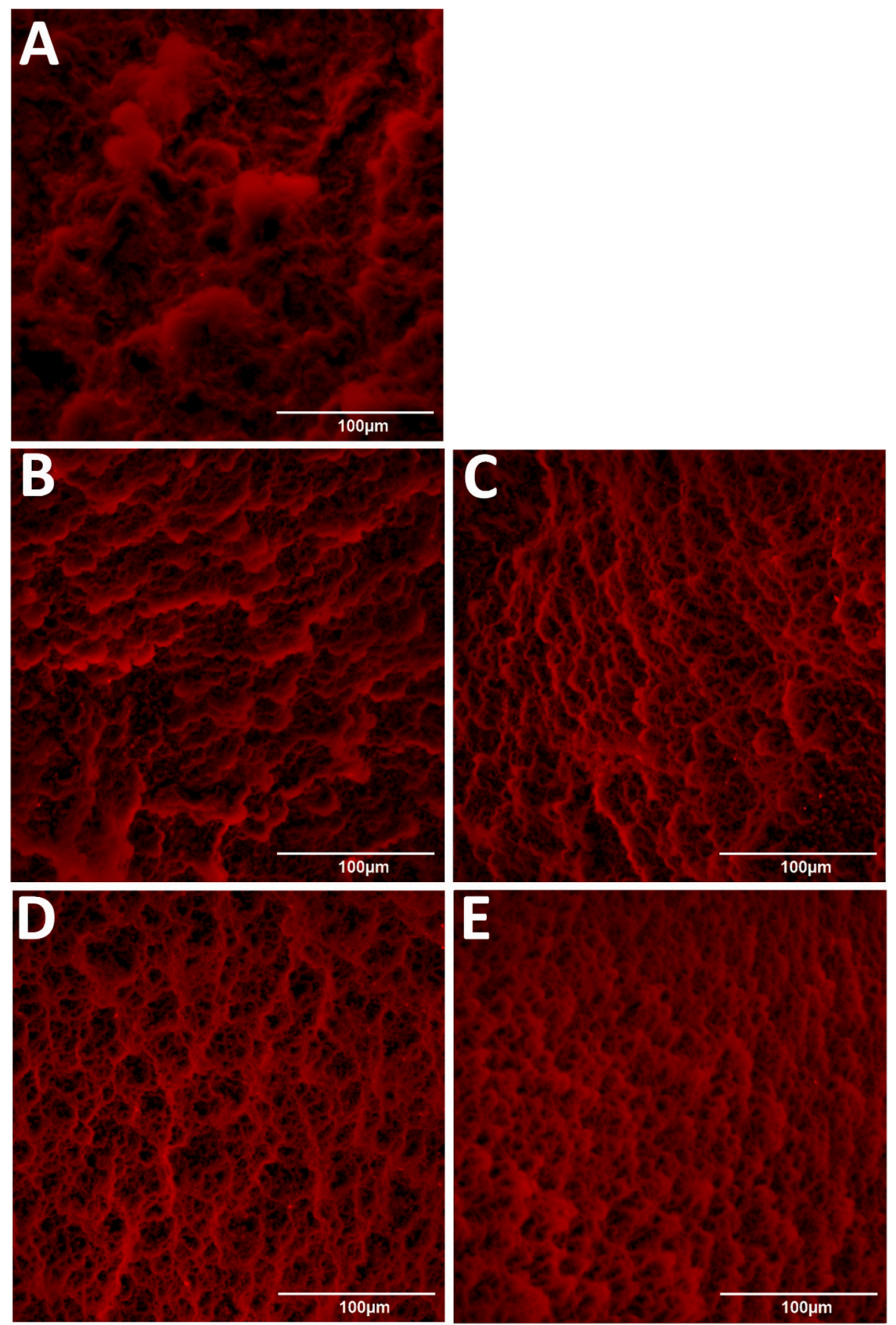

Fig. 2. CLSM photomicrographs of WPI cold-set gels pre-treated by: (A) Cov, (B) $\mathrm{OH} 20 \mathrm{kHz} 10 \mathrm{~V} / \mathrm{cm}$, (C) $\mathrm{OH} 20 \mathrm{kHz} 20 \mathrm{~V} / \mathrm{cm}$, (D) $\mathrm{OH} 50 \mathrm{~Hz} 10 \mathrm{~V} / \mathrm{cm}$ and (E) OH $50 \mathrm{~Hz} \mathrm{EF} 20 \mathrm{~V} \mathrm{~cm}^{-1}$.

mercaptoethanol, a disulphide bond reducing agent, were used in the compositions of extraction media. PB was used as solvent to extract proteins not involved in the network formation and a conjugation of all the bond/interaction disrupting agents was used to very if the summed effects of all agents resulted in the total disruption of the network. The results of the solubility experiments are presented in Fig. 5. For the solvent containing all the agents, the gels presented quick erosion and were no longer visible after a period of a few hours. After the first $24 \mathrm{~h}$, the complete solubilisation of all the gels was verified (results not shown). This demonstrates that the combined action of all the disrupting agents was able to break up all the interactions involved in the network formation. The gels placed in PB presented a solubility of 5\% of their total protein content after $24 \mathrm{~h}$, and remained constant thereafter, throughout the 5 days of the experiment. A visual inspection of the gels through the experiment revealed no apparent changes on the gel size, shape or colour. The small amount of protein dissolved was possibly the protein fraction not included in the network formation, which thus remained in the free state. For the solvents containing the different agents, it was observed an increase of protein solubility over time, with differentiation between samples treated with the various thermoelectric treatments being evaluated. The solvent containing SDS did not cause observable changes within $24 \mathrm{~h}$, however at day 3 and 5 differences between samples' solubility became clear. Samples that suffered an $\mathrm{OH}$ pre-treatment exhibited tendentiously lower solubility in the presence of SDS, reaching significant levels for the samples exposed to $50 \mathrm{~Hz} \mathrm{OH}$ treatments. This lower erosion of the $\mathrm{OH}$ samples in the 

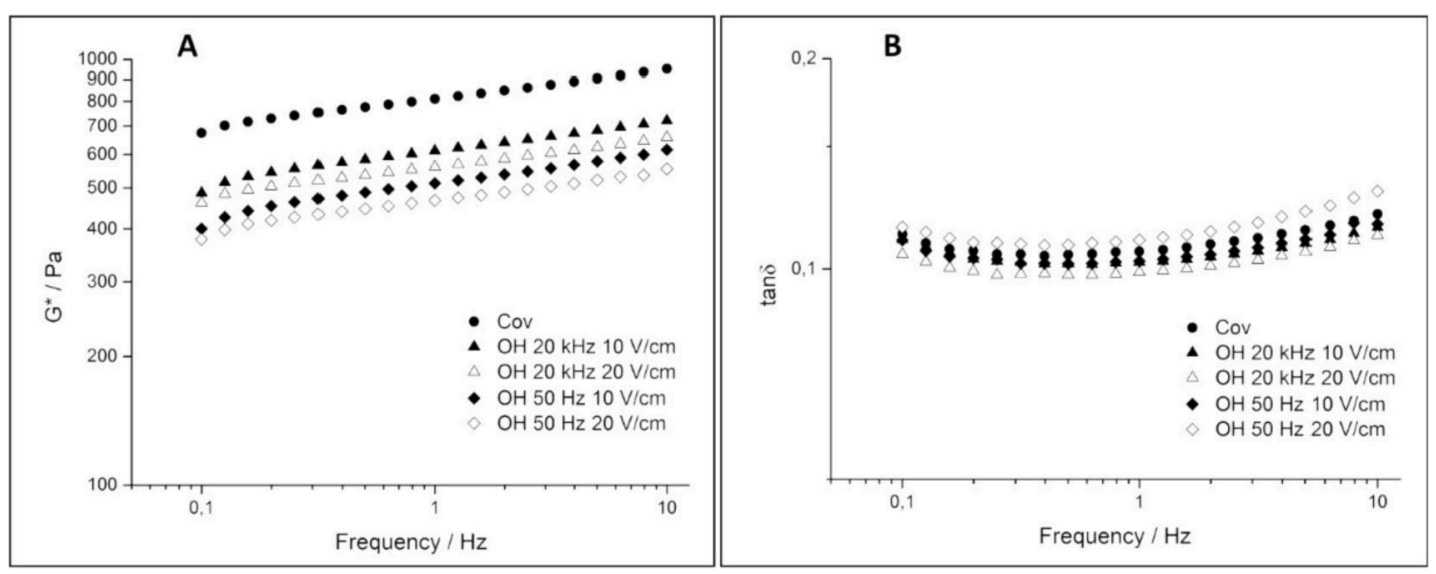

Fig. 3. The frequency dependence of $G^{*}(\mathrm{~A})$ and $\tan \delta$ (B) of the cold-set WPI gels prepared from solutions exposed to different thermo-electric conditions.

Table 3

Effect of thermo-electric conditions on the cold set gels' $G^{*}$ and $\tan \delta$ measured at $1 \mathrm{~Hz}$.

\begin{tabular}{lll}
\hline Sample & $G^{*}(\mathrm{~Pa})$ & $\tan \delta$ \\
\hline Cov & $809.14 \pm 67,07^{\mathrm{a}}$ & $0,104 \pm 0,009^{\mathrm{a}}$ \\
OH $20 \mathrm{kHz} 10 \mathrm{~V} / \mathrm{cm}$ & $623.40 \pm 64,01^{\mathrm{b}}$ & $0,102 \pm 0,006^{\mathrm{a}}$ \\
OH $20 \mathrm{kHz} 20 \mathrm{~V} / \mathrm{cm}$ & $566.79 \pm 62.40^{\mathrm{bc}}$ & $0,100 \pm 0,005^{\mathrm{a}}$ \\
OH $50 \mathrm{~Hz} 10 \mathrm{~V} / \mathrm{cm}$ & $514.29 \pm 29.31^{\mathrm{cd}}$ & $0,104 \pm 0,012^{\mathrm{a}}$ \\
OH $50 \mathrm{~Hz} \mathrm{EF} 20 \mathrm{~V} / \mathrm{cm}$ & $464.24 \pm 51,79^{\mathrm{d}}$ & $0,110 \pm 0,013^{\mathrm{a}}$ \\
\hline
\end{tabular}

For each column, different letters correspond to statistically significant differences $(p<0.05)$.

presence of SDS may be the result of more or stronger hydrophobic interaction within the network. The use of urea resulted on a similar tendency, yet more pronounced and already observable after the first $24 \mathrm{~h}$ of treatment. OH-treated gels were less soluble, displaying significant differences at day 1 for the $50 \mathrm{~Hz}$ treatments and increasing with time. At day 5 the protein solubility of Cov samples reached $27 \%$, the $\mathrm{OH}$ at $20 \mathrm{kHz}$ was $23 \%$ and for the $50 \mathrm{~Hz}$ samples was $17 \%$, with no differences between the different EF strengths used. These differences in urea action reflect on the amount of hydrogen bonds stabilising the network, showing the predominance of these interaction on the $\mathrm{OH}$ treated samples. The use of 2-Me revealed an opposite tendency, with the $\mathrm{OH}$ treated samples displaying higher solubility and thus lower disulphide crosslinking. This behaviour was defined since day 1 but only statistically significant for the $50 \mathrm{~Hz}$ treatments. Throughout the experimental time solubility increases, ranging from $21 \%$ of the Cov samples to $34 \%$ of the $\mathrm{OH}$ at $50 \mathrm{~Hz}$. Like in the previous example, differences were significant for $\mathrm{Cov}$ and $\mathrm{OH}$ treatments and among $\mathrm{OH}$ at different frequencies. Visual inspection of the gels after the experiment was concluded revealed changes in their appearance. Gels exposed to SDS and urea presented considerable swelling and became amorphous, while remaining cohesive. This demonstrate that these interactions contribute to the gel morphology and viscoelastic properties. On the other hand, the gels exposed to 2-Me lost structural integrity and precipitated under the form of insoluble aggregates. The network disruption by the action of 2-Me suggested that disulphide bonds are the critical interactions to maintain the structure integrity. The different solubility in the solvents tested show different physicochemical interactions in the gels produced following the several thermo-electric treatments used. Relatively to the Cov gels, OH-treated samples were more susceptible to disulphide disruption. The lower amount of disulphide crosslinking proposed for the $\mathrm{OH}$-treated samples justifies their higher solubilisation on the solvent containing 2-Me. However, it is interesting to note the higher stability in hydrophobic and hydrogen bond disruption solvents. It has been reported that the application of MEF results in different protein conformations and induces higher hydrophobic groups exposition during protein denaturation (Rodrigues et al., 2019). These facts associated with lower disulphide crosslinking can result in a network with more predominance of hydrophobic interactions stabilized by hydrogen bonds.

\subsubsection{WRC and swelling}

Fig. 6 shows the results obtained for the swelling degree and WRC of the WPI cold-set gels. Once more, the $\mathrm{OH}$-treated samples presented a distinguished behaviour from the Cov samples, with higher values of swelling degree and higher WRC. The EF increase and use of low frequencies tend to increase these parameters; however, no statistically significant differences were found among the $\mathrm{OH}$ samples. The increase of swelling and WRC of the OH-treated gels could be explained by the fact that $\mathrm{OH}$ gels had a finer structure and were less firm (less hard), so the water-protein interactions were favoured. Furthermore, the lower amount of chemical crosslinking, and more physical interactions, resulted on a weaker, more flexible structure, capable to absorb and retain more water.

\section{4. $\mathrm{OH}$ and electric effects on WPI gelation}

In recent reports dealing with external $\mathrm{EF}$ during $\mathrm{OH}$, we have confirmed the ability of MEF to induce changes at molecular level during whey protein denaturation, potentially affecting protein functionality (Rodrigues et al., 2019). In this study, we used the previously established knowledge of $\mathrm{OH}$ effects and $\mathrm{EF}$ variables on whey protein structure and further evaluated them on WPI functionality. OH treatments during the initial protein denaturation and aggregation stage, resulted in smaller aggregates with lower fractions of accessible SH. The higher thermal uniformity typically obtained under $\mathrm{OH}$ and the additional EF effects may influence the protein interaction and aggregation process, favouring disulphide crosslinking and resulting on a faster stabilization of the aggregates. These smaller aggregates, with lower amount of free SH content also resulted in a system with a lower viscosity, when compared with Cov-treated samples. These differentiations were also reflected in the further gelation of the aggregates' solutions, resulting in cold-set gels with a finer network, i.e., a weaker, softer and more elastic structure, with higher WRC and swelling behaviour. Cold-set protein gels' properties are dependent on the pre-heated aggregates characteristics (Ton Van Vliet et al., 2004). Aggregates size and disulphide/free SH content are reported as the main aspects to consider in the network formation and final properties of the gels (Alting, Hamer, de Kruif et al., 2003; Ju \& Kilara, 1998; Nicolai et al., 2011). The lower amount of free SH groups in the aggregates led to lower levels of disulphide crosslinking in the resultant gels and the promotion of physical interactions. This explains the formation of weaker and more flexible gels, with a higher WRC and swelling degree. Also the less rigid 

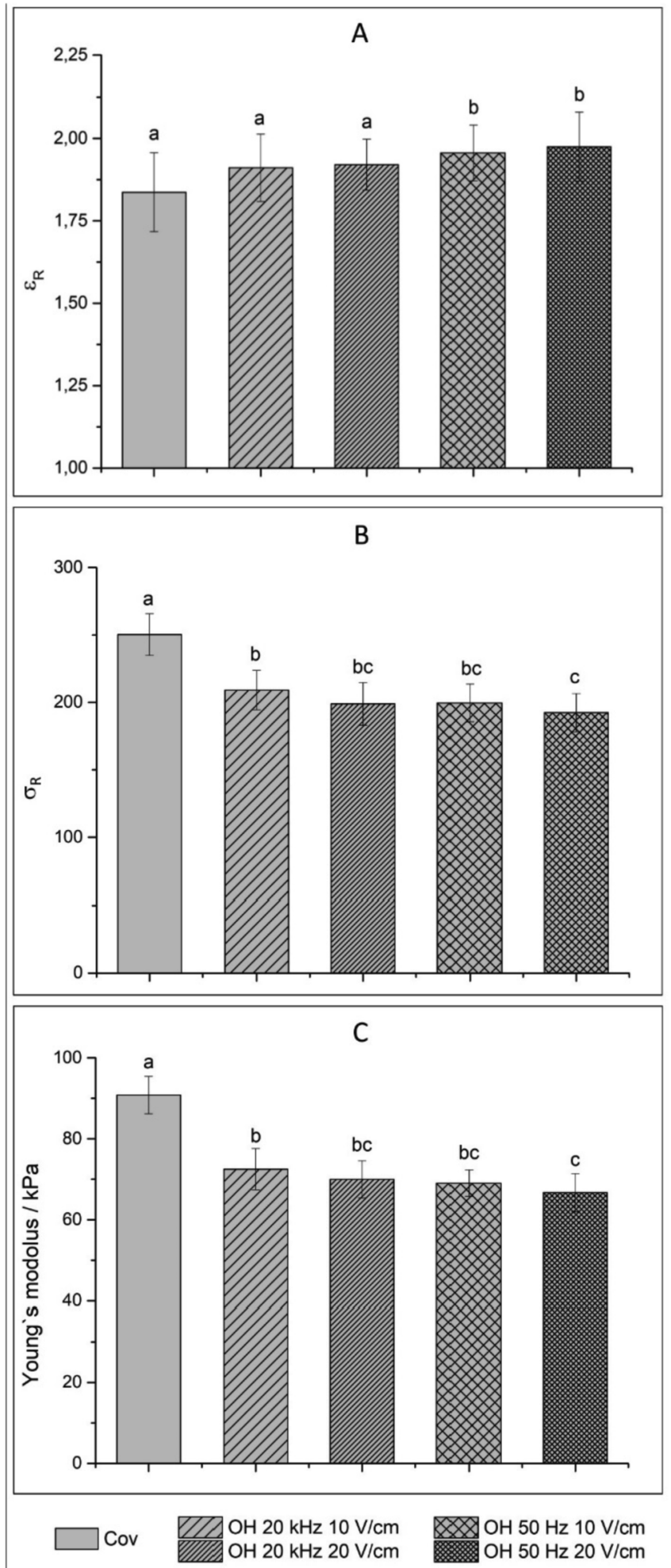

Fig. 4. Mechanical properties of the obtained cold-set gels, (A) strain at rupture $\left(\varepsilon_{R}\right),(\mathrm{B})$ stress at rupture $\left(\sigma_{R}\right)$ and $(\mathrm{C})$ Young's modulus.

networks have a higher capacity to swell and less propensity to expel water (Alting, Hamer, de Kruif et al., 2003). Overall, it was demonstrated that the effects promoted by the presence of EF in protein structure, result on a cascade of events, culminating in changes in the gel functional properties. The electrical field strength and frequency have demonstrated to be relevant in defining structural variations and several aspects of functionality. However, as the complexity of the structures
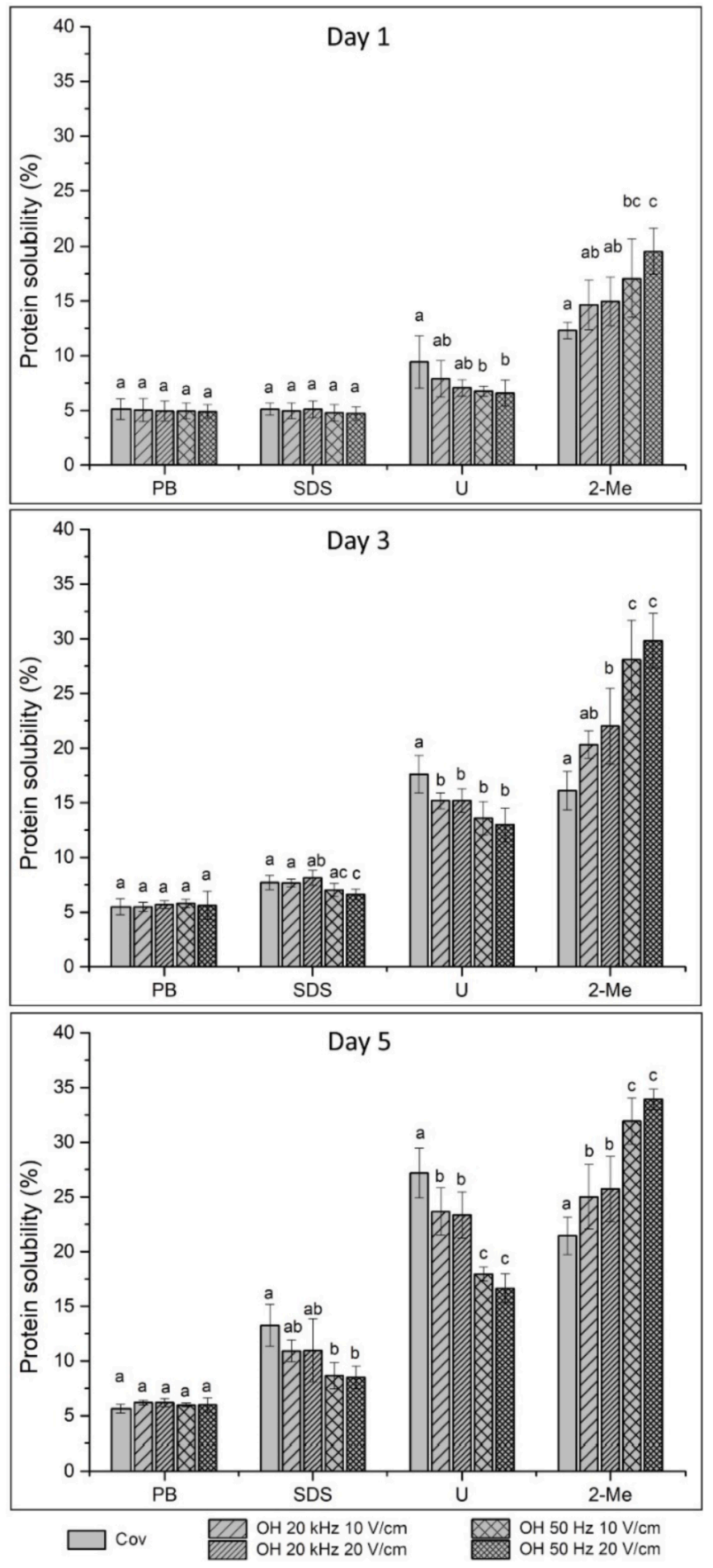

Fig. 5. Protein solubilisation in different solvent systems through a period of 5 days.

increased (i.e. from aggregates to a continuous network) their effects were diluted by other factors involved. Ultimately, the increase of EF strength and especially the use of low frequencies resulted in variations of microstructure, viscoelastic properties, mechanical properties and physicochemical interactions of the gels. However, the EF variables effects were not reflected in WRC and swelling and only the treatment type was significant. The results presented on this study demonstrated the basic mechanism of $\mathrm{OH}$ and its variables on WPI gelation, but further studies are needed to better explore these effects and fully disclosure their potential to tune protein networks. 


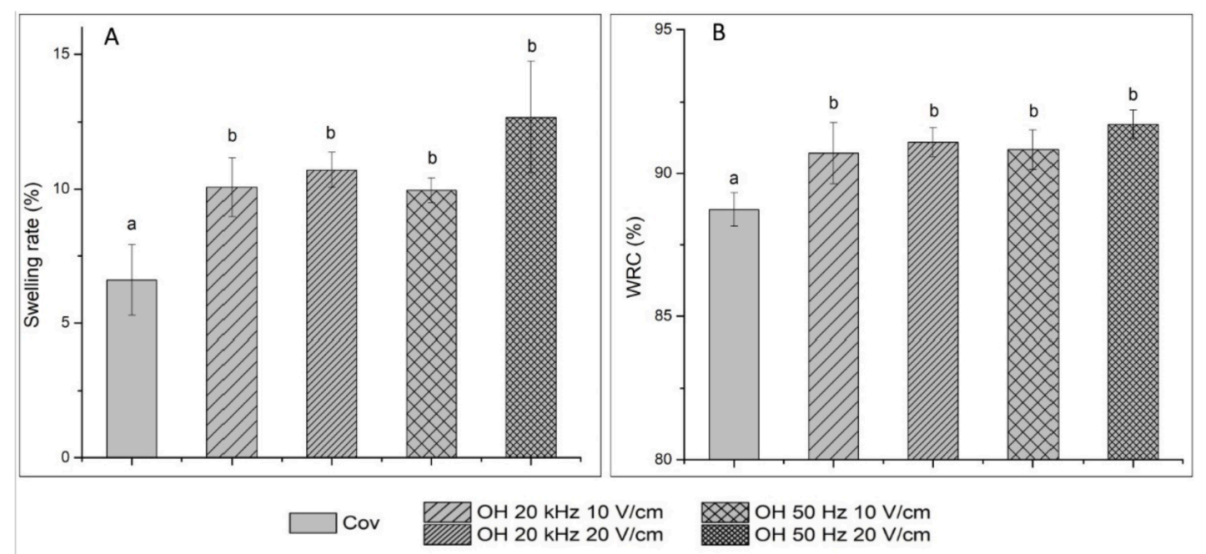

Fig. 6. Swelling degree (A) and WRC (B) of the obtained cold-set gels.

\section{Conclusions}

The use of $\mathrm{OH}$ has demonstrated the potential of changing the gel forming properties of whey proteins. However, the action of MEF during $\mathrm{OH}$ was unclear and its specific effects in the protein structure or aggregation mechanisms remained speculative. In this study, the use of $\mathrm{OH}$ and different electrical variables during WPI pre-treatment resulted in differences in protein aggregation, also reflected on the cold gelation of the WPI aggregates and final gel properties. Furthermore, the electrical variables used contributed to the differentiation of $\mathrm{OH}$-treated samples, being the MEF-related effects potentiated by the increase of EF strength and particularly by the use of low frequencies. To the best of our knowledge, for the first time we have demonstrated that MEF effects at molecular level result in a cascade of events ultimately originating differentiated functional properties. These findings represent a step forward in the understanding of $\mathrm{OH}$ and MEF technological applications. They also contribute to establish EF-based technologies as potential tools to change and control protein functionality and potential applications.

\section{Declaration of competing interest}

The authors declare that they have no known competing financial interests or personal relationships that could have appeared to influence the work reported in this paper.

\section{Acknowledgments}

This study was supported by the Portuguese Foundation for Science and Technology (FCT) under the scope of the strategic funding of UID/ BIO/04469/2013 unit and COMPETE 2020 (POCI-01-0145-FEDER006684) and BioTecNorte operation (NORTE-01-0145-FEDER-000004) funded by European Regional Development Fund under the scope of Norte2020, Programa Operacional Regional do Norte. Rui M. Rodrigues gratefully acknowledge FCT for their financial grants with references SFRH/BD/110723/2015.

\section{References}

Ako, K., Nicolai, T., \& Durand, D. (2010). Salt-induced gelation of globular protein aggregates: Structure and kinetics. Biomacromolecules, 11(4), 864-871. https://doi. org/10.1021/bm9011437.

Alting, A. C., Hamer, R. J., de Kruif, C. G., Paques, M., \& Visschers, R. W. (2003). Number of thiol groups rather than the size of the aggregates determines the hardness of cold set whey protein gels. Food Hydrocolloids, 17(4), 469-479. https://doi.org/10.1016/ S0268-005X(03)00023-7.

Alting, A. C., Hamer, R. J., De Kruif, C. G., \& Visschers, R. W. (2003). Cold-set globular protein gels: Interactions, structure and rheology as a function of protein concentration. Journal of Agricultural and Food Chemistry, 51(10), 3150-3156. https://doi.org/10.1021/jf0209342.
Amin, S., Barnett, G. V., Pathak, J. A., Roberts, C. J., \& Sarangapani, P. S. (2014). Protein aggregation, particle formation, characterization \& rheology. Current Opinion in Colloid \& Interface Science, 19(5), 438-449. https://doi.org/10.1016/j. cocis.2014.10.002.

Bryant, C. M., \& McClements, D. J. (1998). Molecular basis of protein functionality with special consideration of cold-set gels derived from heat-denatured whey. Trends in Food Science \& Technology, 9(4), 143-151. https://doi.org/10.1016/S0924-2244(98) 00031-4.

Chi, E. Y., Krishnan, S., Randolph, T. W., \& Carpenter, J. F. (2003). Physical stability of proteins in aqueous solution: Mechanism and driving forces in nonnative protein aggregation. Pharmaceutical Research, 20(9), 1325-1336. https://doi.org/10.1023/ A:1025771421906.

De Vries, H., Mikolajczak, M., Salmon, J. M., Abecassis, J., Chaunier, L., Guessasma, S., et al. (2018). Small-scale food process engineering - challenges and perspectives. Innovative Food Science \& Emerging Technologies, 46(March), 122-130. https://doi. org $/ 10.1016 /$ j.ifset.2017.09.009.

Ellman, G. L., Courtney, K. D., Andres, V., \& Featherstone, R. M. (1961). A new and rapid colorimetric determination of acetylcholinesterase activity. Biochemical Pharmacology, 7(2), 88-95. https://doi.org/10.1016/0006-2952(61)90145-9.

Guo, M. (Ed.). (2019). Whey protein production, chemistry, functionality, and applications. Chichester, UK: John Wiley \& Sons, Ltd. https://doi.org/10.1002/9781119256052.

Jaeger, H., Roth, A., Toepfl, S., Holzhauser, T., Engel, K. H., Knorr, D., et al. (2016). Opinion on the use of ohmic heating for the treatment of foods. Trends in Food Science \& Technology, 55, 84-97. https://doi.org/10.1016/j.tifs.2016.07.007.

Ju, Z. Y., \& Kilara, A. (1998). Gelation of $\mathrm{pH}$-aggregated whey protein isolate solution induced by heat, protease, calcium salt, and acidulant. Journal of Agricultural and Food Chemistry, 46(5), 1830-1835. https://doi.org/10.1021/jf9710185.

Kaur, N., \& Singh, A. K. (2016). Ohmic heating: Concept and applications-a review. Critical Reviews in Food Science and Nutrition, 56(14), 2338-2351. https://doi.org/ $10.1080 / 10408398.2013 .835303$.

Mleko, S., \& Foegeding, E. A. (2000). pH induced aggregation and weak gel formation of whey protein polymers. Journal of Food Science, 65(1), 139-143. https://doi.org/ 10.1111/j.1365-2621.2000.tb15969.x.

Nicolai, T., Britten, M., \& Schmitt, C. (2011). $\beta$-Lactoglobulin and WPI aggregates: Formation, structure and applications. Food Hydrocolloids, 25(8), 1945-1962. https://doi.org/10.1016/j.foodhyd.2011.02.006.

Pereira, R. N., Rodrigues, R. M., Altinok, E., Ramos, Ó. L., Xavier Malcata, F., Maresca, P., et al. (2017). Development of iron-rich whey protein hydrogels following application of ohmic heating - effects of moderate electric fields. Food Research International, 99, 435-443. https://doi.org/10.1016/j.foodres.2017.05.023.

Pereira, R. N., Rodrigues, R. M., Ramos, O. L., Malcata, F. X., Teixeira, J. A., \& Vicente, A. A. (2016). Production of whey protein-based aggregates under ohmic heating. Food and Bioprocess Technology, 9(4), 576-587. https://doi.org/10.1007/ s11947-015-1651-4.

Pereira, R. N., Souza, B. W. S., Cerqueira, M. A., Teixeira, J. A., \& Vicente, A. A. (2010). Effects of electric fields on protein unfolding and aggregation: Influence on edible films formation. Biomacromolecules, 11(11), 2912-2918. https://doi.org/10.1021/ bm100681a.

Priyadarshini, A., Rajauria, G., O’Donnell, C. P., \& Tiwari, B. K. (2018). Emerging food processing technologies and factors impacting their industrial adoption. Critical Reviews in Food Science and Nutrition, O(0), 1-20. https://doi.org/10.1080/ 10408398.2018.1483890.

Ramos, O. L., Pereira, R. N., Rodrigues, R., Teixeira, J. A., Vicente, A. A., \& Xavier Malcata, F. (2014). Physical effects upon whey protein aggregation for nano-coating production. Food Research International, 66. https://doi.org/10.1016/j. foodres.2014.09.036.

Rodrigues, R. M., Martins, A. J., Ramos, O. L., Malcata, F. X., Teixeira, J. A., Vicente, A. A., et al. (2015). Influence of moderate electric fields on gelation of whey protein isolate. Food Hydrocolloids, 43, 329-339. https://doi.org/10.1016/j. foodhyd.2014.06.002.

Rodrigues, R. M., Vicente, A. A., Petersen, S. B., \& Pereira, R. N. (2019). Electric field effects on $\beta$-lactoglobulin thermal unfolding as a function of $\mathrm{pH}$ - impact on protein 
functionality. Innovative Food Science \& Emerging Technologies, 52, 1-7. https://doi. org/10.1016/j.ifset.2018.11.010. October 2018.

Rosenthal, A. J. (1999). Food texture: Measurement and perception. U.S: Aspen Publishers Inc.

Ross-Murphy, S. B. (1995). Structure-property relationships in food biopolymer gels and solutions. Journal of Rheology, 39(6), 1451-1463. https://doi.org/10.1122/ 1.550610 .

Sastry, S. (2008). Ohmic heating and moderate electric field processing. Food Science and Technology International, 14(5), 419-422. https://doi.org/10.1177/

1082013208098813.
Savadkoohi, S., \& Farahnaky, A. (2012). Dynamic rheological and thermal study of the heat-induced gelation of tomato-seed proteins. Journal of Food Engineering, 113(3), 479-485. https://doi.org/10.1016/j.jfoodeng.2012.06.010.

Steffe, J. F. (1996). Rheological methods in food process engineering. Freeman Press.

van Vliet, T. (2000). Structure and rheology of gels formed by aggregated protein particles. In Hydrocolloids (pp. 367-377). Elsevier. https://doi.org/10.1016/B978044450178-3/50047-0.

van Vliet, T., Lakemond, C. M. M., \& Visschers, R. W. (2004). Rheology and structure of milk protein gels. Current Opinion in Colloid \& Interface Science, 9, 298-304. https:// doi.org/10.1016/j.cocis.2004.09.002. 